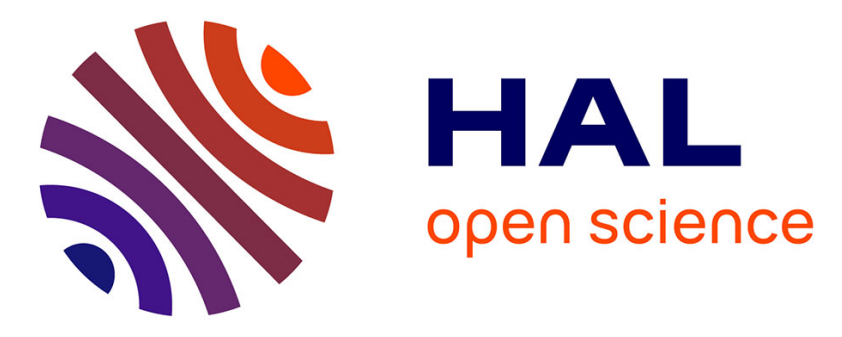

\title{
Linking Modular Product Structure to Suppliers' Selection Through PLM Approach: A Frugal Innovation Perspective
}

Farouk Belkadi, Ravi Kumar Gupta, Ekaterini Vlachou, Alain Bernard, Dimitris Mourtis

\section{To cite this version:}

Farouk Belkadi, Ravi Kumar Gupta, Ekaterini Vlachou, Alain Bernard, Dimitris Mourtis. Linking Modular Product Structure to Suppliers' Selection Through PLM Approach: A Frugal Innovation Perspective. 13th IFIP International Conference on Product Lifecycle Management (PLM), Jul 2016, Columbia, SC, United States. pp.227-237, 10.1007/978-3-319-54660-5_21 . hal-01699723

\section{HAL Id: hal-01699723 \\ https://hal.inria.fr/hal-01699723}

Submitted on 2 Feb 2018

HAL is a multi-disciplinary open access archive for the deposit and dissemination of scientific research documents, whether they are published or not. The documents may come from teaching and research institutions in France or abroad, or from public or private research centers.
L'archive ouverte pluridisciplinaire HAL, est destinée au dépôt et à la diffusion de documents scientifiques de niveau recherche, publiés ou non, émanant des établissements d'enseignement et de recherche français ou étrangers, des laboratoires publics ou privés.

\section{(c)(1)}

Distributed under a Creative Commons Attribution| 4.0 International License 


\title{
Linking modular product structure to suppliers' selection through PLM approach: A Frugal innovation perspective
}

\author{
Farouk Belkadi $^{1}$, Ravi Kumar Gupta ${ }^{1}$, Ekaterini Vlachou ${ }^{2}$, \\ Alain Bernard ${ }^{1}$, Dimitris Mourtis ${ }^{2}$ \\ ${ }^{1}$ Ecole Centrale de Nantes - IRCCyN - UMR CNRS 6597 \\ 1 rue de la Noë, Nantes 44300, France \\ ${ }^{2}$ Laboratory for Manufacturing Systems and Automation (LMS), \\ Department of Mechanical Engineering and Aeronautics, \\ University of Patras, Rio Patras, Greece, 26504
}

\begin{abstract}
To maintain market share rates, frugal innovation is a main solution for competitive enterprises to meet the customer's needs in different regional markets. The co-evolution of product and production network aims to manage local production sites of the OEM and several collaborative relations between OEM and supplier companies for better management of the project resources in the regional market. Supplier selection and evaluation are among the main factors to be resolved at the earlier stage to guarantee successful results from any OEM-Supplier collaboration. This paper discusses the potential of using a modular-based approach as a kernel methodology to support the co-evolution of product structure and production network definition, especially in the case of supplier selection for frugal innovation perspective. The application of PLM approach to manage interconnected data describing the co-evolution of the product structure and production network is also discussed.
\end{abstract}

Keywords: PLM; co-evolution; Modular; Supplier selection; frugal innovation

\section{Introduction}

In context of hard competitiveness and economic pressures, companies need to reach new markets (i.e. both emerging and mature market) by further sharpening their strategic focus on what customers really need. For this, frugal innovation theory is introduced to explain new market trends and to propose new solutions supporting these evolutions [1]. For Tiwari and Herstatt [2], frugal innovation refers to innovative products and services that "seek to minimize the use of material and financial resources in the complete value chain (from development to disposal) with the objective of reducing the cost of ownership while fulfilling or even exceeding certain pre-defined criteria of acceptable quality standards".

This theory results new category of products named "frugal" as an aggregation of the following attributes: Functional to answer the exact customer need by focusing on key product features; Robust with integration of recent technologies and facilities of maintenance high life duration; User-friendly through a simple and easy to use 
functions and interfaces; Growing through large production volumes enabling economies of scale; Affordable by offering to customer good "value for his money" through adaptable prices according to their socio-economic context; and Local to propose products mainly tailored to local requirements but also built using some production facilities (i.e. suppliers) and components from the targeted market [3].

To develop such kind of products, companies should adopt a customer-driven design process and an optimal co-evolution of the production strategy to reduce manufacturing and logistic costs, taking in consideration the capabilities, constraints and resources available in the targeted market. The design strategy respecting frugal attributes can be conducted through a set of following design actions:

- Design new specific modules or modifying the features of existing ones,

- Reuse existing solutions developed by the company in previous projects,

- Use standard modules developed by external suppliers for several products.

The co-evolution of the production network to support the adaptation of an existing product to a new market implies new changes on the production process or on suppliers to cope with new modification in the product structure (it can be the change of one module or modification of some module features). In parallel, the modification of the product structure can be a consequence of using a new module (or technology) proposed by a supplier in the local market which results in the co-evolution of the product structure with the production strategy [4]. The big challenge is then to have an efficient collaboration between the OEM company and all its suppliers.

The co-evolution of the production system should be extended to the production network level that aims to create several collaborative relations between the OEM (Original Equipment Manufacturer) and suppliers' companies for better management of their distinctive skills and resources in the whole production process [5]. Thus, Supplier selection and evaluation are among the main factors to be resolved at the earlier stage to guarantee successful results from any OEM-Supplier collaboration [6].

As per our study, an emerging market's needs can be solved by adapting an existing product and production which are well stablished in westerned and European markets to fulfil regional customer's requirements (new market) especially when the customer belongs to emerging markets (e.g. India, Africa and China). This adaptation of the existing product to emerging market is researched using frugal innovation. Few companies adopted the frugal innovation for the above aspects, but took long time to launch their product in the markets.

The research in ProRegio [7] is to fill these gaps. One part in this research is suppliers' selection respecting the requirements from regional markets and also company's policies.

In this context, this paper discusses the potential of using a modular-based approach as a kernel methodology to support the co-evolution of product structure and production network definition, especially in the case of supplier selection in context of frugal innovation. This approach is mainly suitable for design strategies based on the use of standard modules or the reuse of existing solutions (with possible adaptation). A smart algorithm is used to generate and evaluate the alternative supplier networks. 


\section{PLM approach for supplier selection}

\subsection{Frugal innovation and suppliers' selection}

With respect to the frugal innovation principle, the global modular-based approach should handle the easier interpretation of customer requirements and the identification of only concerned modules to be considered for the customization process $[8,9]$.

The concept of module represents a physical or conceptual grouping of product components to form a consistent unit that can be easily identified and replaced in one product architecture in order to increase product variety and flexible adaptability [10].

In the proposed frugal innovation process (Figure 1), the designer can propose several alternatives of product modules with specific features to cope with a set of customer requirements. These features concern technical characteristics used for the engineering perspective as well as useful inputs for building the related production network. Each module is identified with all possible production capabilities or suppliers able to provide it with the desired characteristics. The selection of the best alternatives of production systems or suppliers is fulfilled by taking in consideration of different facilities and constraints in the local market to build the global production network. Then the selection of the best module solutions can be obtained as a consequence of selecting the related production systems or suppliers.

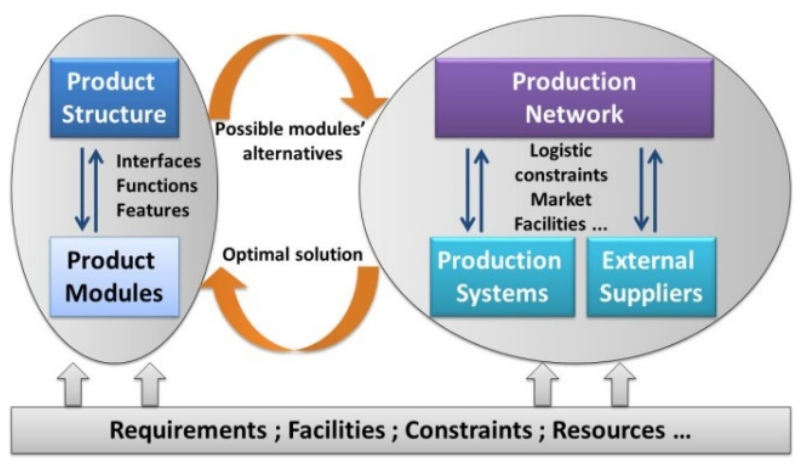

Fig 1. Co-definition of product structure and production network

Production system refers to technological elements (machines and tools), organizational behavior and managing resources within OEM whereas supplier refers to external supplier of product modules and related supports. A supplier can be local or international based on local requirements and product modules characteristics.

By fixing the different production systems and suppliers (for final assembly and for the production of modules), the structure of the production network is defined as a combination of the selected items. The expected behavior of the network is obtained by the definition of the global planning and all collaborative processes supporting information and material exchange among these production systems and suppliers. Thus, the assembly process of the whole product structure is obtained according to the global production planning at network level. 
Several collaborative relations between the OEM and suppliers are identified in the literature based on the level of integration of the supplier in the final project of the OEM [11]. At the low levels, suppliers are assimilated to simple executors of detailed specifications from the OEM. In more collaboration level, the supplier is more involved in the development project and participates to the definition of the product architecture ( $1^{\text {st }}$ rank suppliers).

This nature of collaboration can provide serious advantages for the deployment of frugal innovation strategy in new markets. In this case the OEM will exploit some interesting and innovative solutions proposed by suppliers to design new frugal product or to adapt an existing one to one specific market. By this, the development process will follow a concurrent path in which the selection of the best product modules can be obtained from the identification of the best suppliers respecting the frugal requirements. Supplier selection strategy contributes principally to the improvement of "Robust", "”Affordable" and "Local" attributes since it gives the possibility to the company to: use new solution that can enhance the product quality respecting the target market standard, moderate the cost by selling from competitive suppliers, especially when those ones are coming from the target market.

The concept of product module can be used to connect the product structure to different outputs of the suppliers involved in the related production network. Thus, using product module features combined with additional information from the final assembly process planning and logistic constraints in the local market can give interesting requirements for the evaluation of KPIs (Key performance indicators) useful to get an impartial assessment of potential suppliers' capacities before considering them in the production network.

The mapping of product module features (from product configuration view) to KPIs (suppliers selection view) is presented in Figure 2. The product modules are the products of the suppliers. The decision making for supplier selection and product module selection is based on the mapping between requirements (product module features) and real values of KPIs for the suppliers and their products.

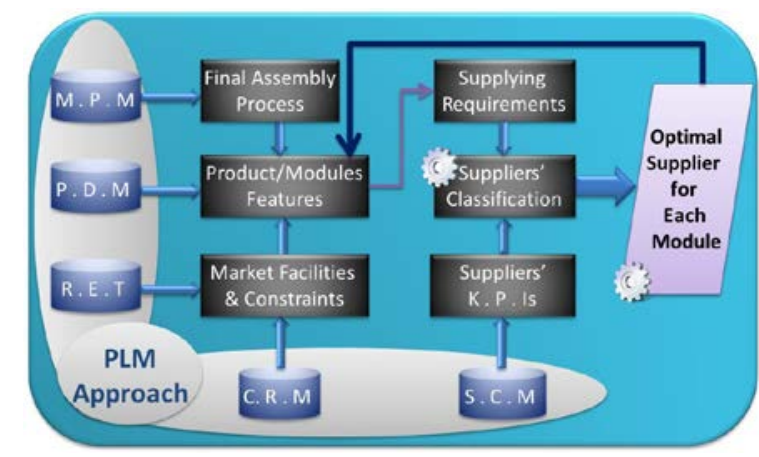

Fig 2. Global PLM approach for supplier selection

The role of mapping is to classify all available suppliers according to the matching level between their KPI values (representing real assessment) and product features (representing requirements). Some time, when there are limited possibilities of 
suppliers to cover the requested module, the mapping table can be used to adapt, if necessary, some product features according to the capacities of the related supplier.

The PLM approach can support the concurrent design process of frugal products and the supplier network through a smart management of product modules and related suppliers alternatives for several product configurations addressed to various markets. This is ensured through an optimal integration, storage and connection of numerous data coming from several applications, including suppliers' selection tools. Indeed, the implementation of PLM approach results from the integration between heterogeneous IT systems such as ERP (Enterprise Resource Planning), PDM (Product Data Management), SCM (Supply Chain management), etc. [12].

In the proposal, the supplier selection process is achieved based on several data stored on different business tools. This data is identified and managed in the PLM system as specific features connected to different product modules alternatives. Each module is analyzed to generate supplying requirements. The final decision is the identification of optimal "Modules-Suppliers" combination as fragment co-definition of best product structure and supplier network with respect to frugal attributes.

\subsection{Product features for supplier selection}

To illustrate the proposed principle of solution for the use of modularity for supplier selection problem, an example of concurrent design process of frugal product and identification of possible suppliers for each module is presented in Figure 3. This scenario deals with the case of adapting existing product architecture to a new market based on the capabilities of existing suppliers in the targeted market.

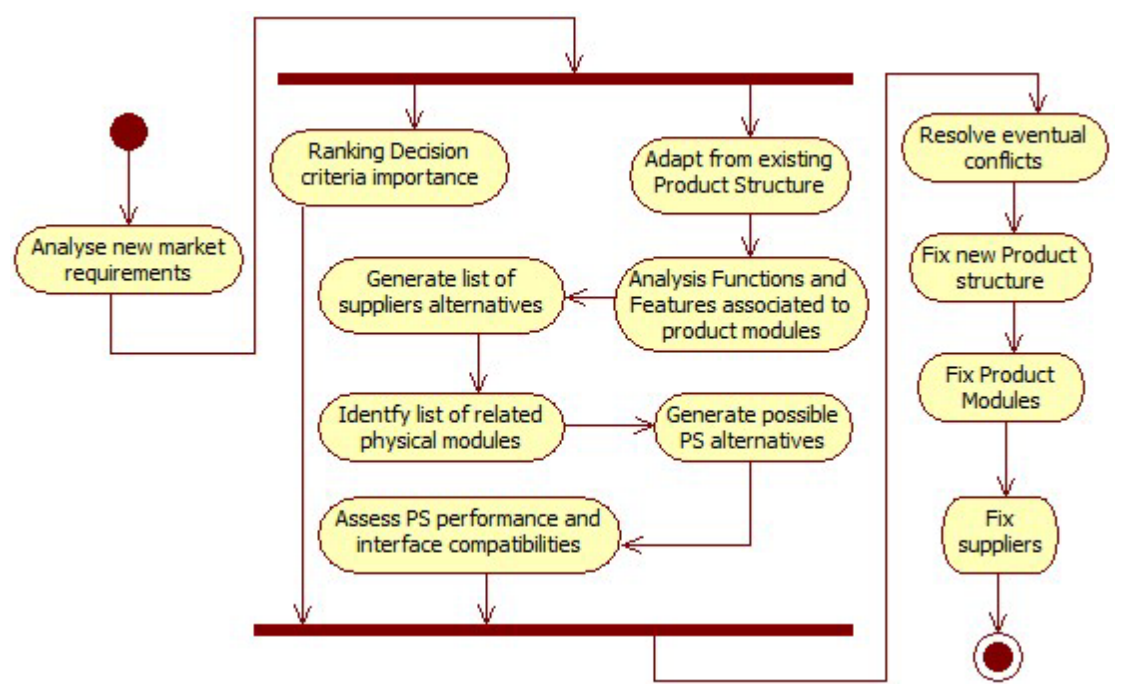

Fig 3. Supplier selection strategy based on global modular product design approach

The process starts by the analysis of new market requirements (including specific customer requirements) and then search for existing product structures covering these 
needs. The analysis of modules functions and features as requirements is used to generate list of possible suppliers. The list of suppliers' alternatives will provide list of possible module alternatives matching with the same functions of the originally design product. Then several alternatives of product structures from the original one (developed in older projects) can be obtained as combination of the product modules proposed by the selected suppliers.

The performance assessment of each alternative will help to fix the best product structure and consequently the best product modules replacing the original ones. In final the list of supplier is fixed as those providing the selected modules.

To perform these decision making processes, additional categories of information should be embedded in the product module concept. The definition of product module through features is to connect different views of the product design and development.

Product module features are defined to translate the regional customer requirements to product design and connect the product design to production planning and supplier network design. The product modules' features are defined to address three categories objectives as inputs for frugal decision making problems regarding the objectives of the global modular product design approach:

- Analyzing customer/market requirements and linking product modules to requested functions in specific product architecture.

- Defining modules' parameters and its interfaces to support the design of new product (and related alternatives) as a consistent combination of product modules.

- Responding to production strategy (production system and network definition) through a consistent connection of modules to optimal production capabilities.

These three categories of features are used to identify requirements for supplying properties and production planning as well as to refine the selection of product module. From these categories of features, the following Table 1 includes the list of relevant features that should be used as requirements for supplier selection process.

Table 1. List of modules features for supplier selection process

\begin{tabular}{|c|l|}
\hline Feature & \multicolumn{1}{|c|}{ Description } \\
\hline Performance & $\begin{array}{l}\text { Acceptable standardization and tolerance level for product module } \\
\text { performance values, regarding the global product performance. }\end{array}$ \\
\hline Interfacing & Capacity to one module to be interfaced with other ones \\
\hline $\begin{array}{c}\text { Interchange- } \\
\text { ability }\end{array}$ & $\begin{array}{l}\text { Capacity for one module to be replaced by one or more other modules } \\
\text { from other suppliers but providing similar functions. }\end{array}$ \\
\hline Customization & $\begin{array}{l}\text { Requested possibility to change some proprieties of the module and } \\
\text { level of options proposed in the supplied module. }\end{array}$ \\
\hline $\begin{array}{c}\text { Process } \\
\text { position }\end{array}$ & $\begin{array}{l}\text { Connection of the module to different steps of the final assembly } \\
\text { process and the level of dependency with the connected modules }\end{array}$ \\
\hline Criticality & $\begin{array}{l}\text { The importance of the related function regarding its added value to } \\
\text { the final product structure. }\end{array}$ \\
\hline $\begin{array}{c}\text { Supplying } \\
\text { tolerance }\end{array}$ & $\begin{array}{l}\text { Level of request on the supplier in terms of cost, delivery time and } \\
\text { confidence level as a consequence of the previous modules' features. }\end{array}$ \\
\hline
\end{tabular}


Figure 4 illustrates an example of using product module features (green color rectangle) to analyze product life cycle and generate additional Supplying Tolerance Features (inner blue color rectangle), to be considered as requirements for decision criteria for the selection of best suppliers for frugal innovation issue. These supplying decision criteria and/or related KIPs can be used for production network design.

Through the application of the concurrent design of product structure and suppliers' network, conflict can appear from contradictions on results based on analysis of product module features on one side and supplying requirements on the other side, for example a module can have high performance but real risk on delivery time regarding the supplier capacities, especially if the module is requested earlier in the production process. This will imply important delays on the final assembly process of the product. Affordable and growing attributes are seriously affected.

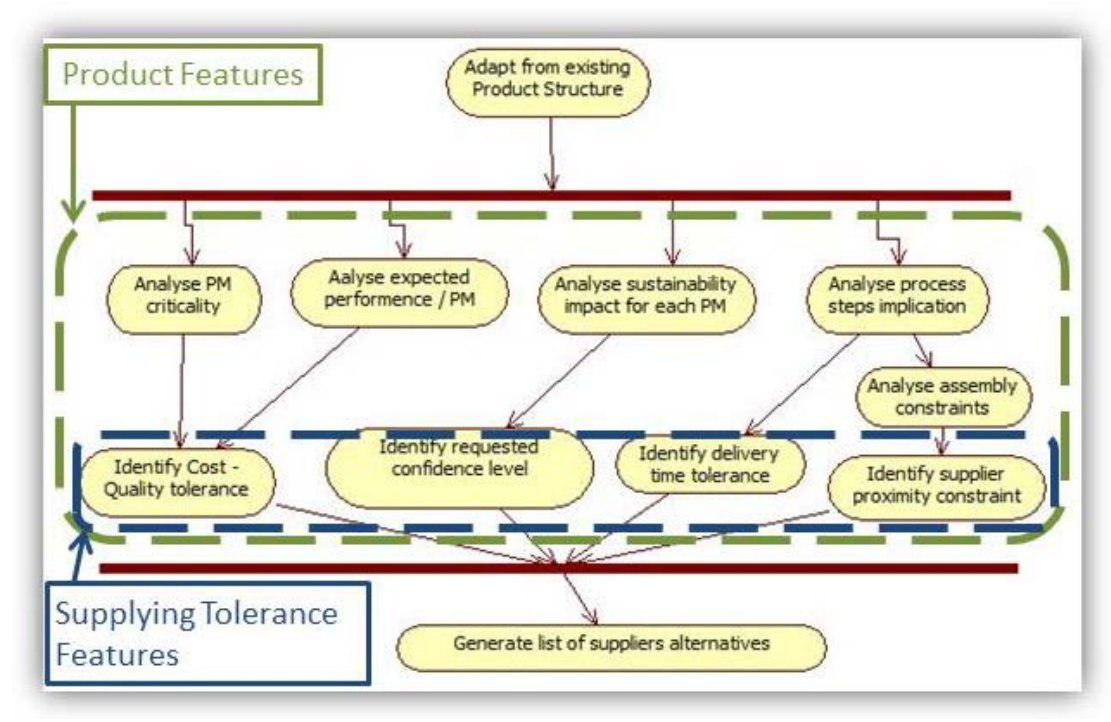

Fig 4. Product module features as requirements for supplying decision criteria

Figure 5 illustrates such kind of conflicts between product modules "as designed" (inner blue color rectangle) and real modules "as produced by suppliers" (inner green color rectangle). It is shown that the product module "PM1" has product module feature "Criticality" value as "High". PM1.1 is the "Best" implementation and PM1.2 is the "Worst" one according to the related suppliers KPIs. However, PM1.1 presents a low level of interfacing with the PM 2.1 that is the only possible implementation of PM2. The conflict is that if the best product module with high criticality (PM1.1) is selected then supplying of other product module (PM2) is not possible.

There are two possibilities to resolve this type of situations either (i) Select the modules to be supplied as per the requested module features and redesign (or reselect new supplier) the product modules which are not possible to be supplied by any existing supplier, or (ii) Relax features' values for the conflicted product module in the requested product. Thus, product module features and KPIs for production 
network design should be connected together through the PLM approach to evaluate all possible combinations of product-suppliers in the production network.

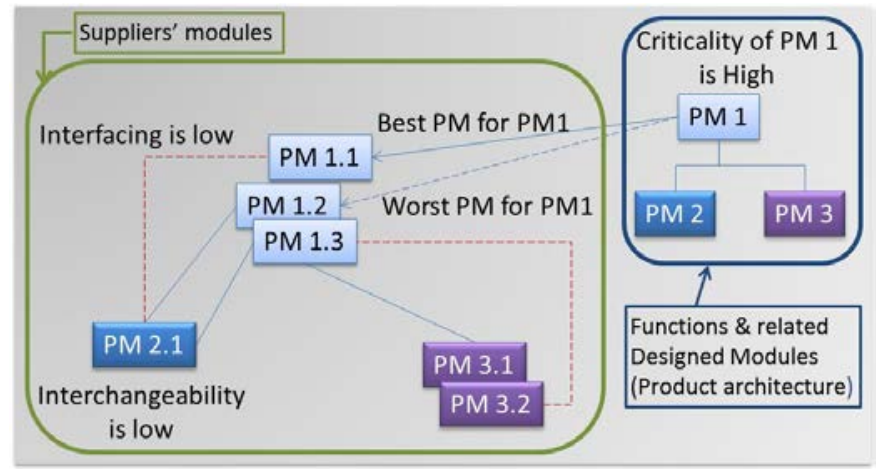

Fig 5. Conflicts possibilities on the co-definition of product structure and supplier network

This connection provides real positive impacts on the frugal attributes. For instance, deciding optimal supplier based not only on its own properties but also on the criticality of the related modules allows managers adapting the balance between product cost and quality by favoring reputable suppliers for the critical modules (high function criticality requesting high quality) even the price is high, and obtaining the less critical modules (less added value for the target market) from low cost suppliers.

\section{Supplier selection and network design method}

The supplier selection and network design method should be capable of generating alternative combinations of product-suppliers and evaluate their performance based on multiple and conflicting criteria based on the constrains-suggestions provided by the design during the generation of the different product structures. One of the main challenges during the supplier's selection and the supplier networks design is to select the optimum supplier based on their suitability and their availability. Therefore, the proposed work proposes a smart search algorithm capable of subset of total number of alternative manufacturing network configurations by utilizing three adjustable parameters [13]. The three control parameters that are utilized are the maximum number of alternatives (MNA) which controls the breadth of the search, the decision horizon (DH) which controls the depth of the search, and the sampling rate (SR) which guides the search towards the high quality branches of the tree of alternatives [14]. The optimum values of these factors will be obtained through a statistical Design of Experiments (SDoE) [15].

The main inputs of the proposed algorithm are the various product features generated by the product configuration and the pre-filtered list of suppliers based on their compatibility and their suitability, as well the bill of processes to produce the product modules and in general the final product. The decision-making procedure following by the supplier selection and networks design algorithm is based on 
resource-task assignment decisions. Considering that, in order to produce a part/module of the product a task should be performed by a resource and the resource belongs to a plant or to a supplier. In case of suppliers the task is directly connected with the supplier.

The main steps of the proposed algorithm the formalization of the alternatives, the criteria determination to satisfy the objectives, the definition of the criteria weights, the calculation of the criteria values and last is the selection of the optimum alternative based on their performance (Figure. 6) [14,16].

Multiple and conflicting criteria are considered and are calculated by the smart search algorithm and during the decision making procedure. Production and Transportation Cost, Quality, Lead time, total Energy Consumption, CO2 emissions are among the main criteria considered [17].

To address the need of frugal innovation in the context of the supplier's selection method also the locality of the suppliers is considered as main criterion. Locality shows how close to the targeted market is the supplier. This will contribute to enhance the affordable and local attributes by reducing logistics costs and using existing standards in the target market since the providers are coming from the same market. Moreover, through the consideration of Locality, as criterion, local suppliers can be considered, increasing the market share of local markets.

The total network performance is calculated by measuring defined KPIs. In that stage, also the suggested KPIs, from the product configuration stage, are considered. The final results of the selected network are sending back to the PLM tool in order to fix the different modules of the product and finalize the design of the product.

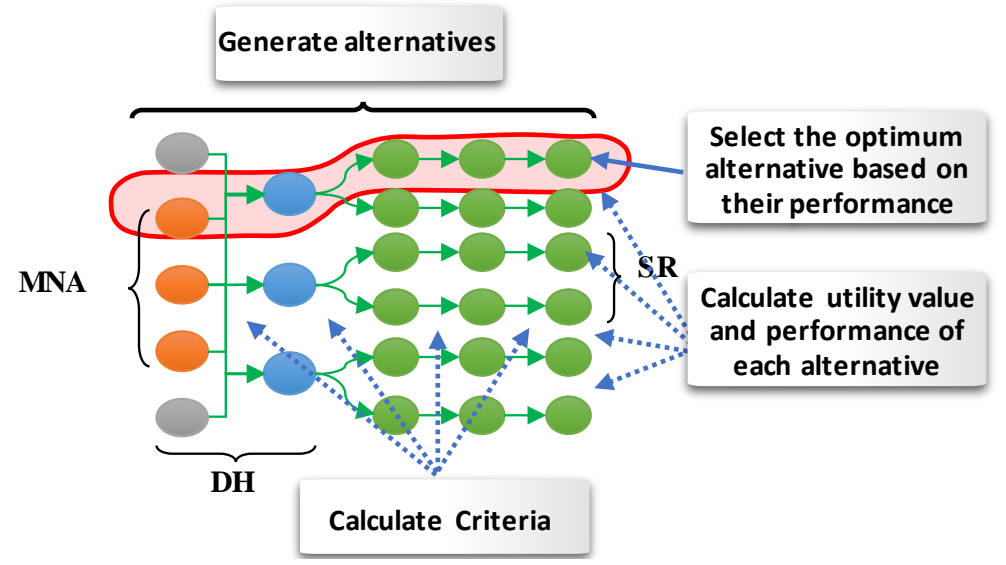

Fig 6. Supplier selection and network design Algorithm-Smart search algorithm

\section{Conclusion}

The co-evaluation of product structure, production systems, and production network has been introduced as a key factor for the success of an enterprise in emerging markets to answer local needs by optimal utilization of local and global capabilities, 
constraints and resources. Global modular approach has been used to support the design and development of frugal product. The application of module concept for frugal innovation perspectives showed the need to re-think the definition of the product model and its integration in future generation of PLM systems. New features should be considered to represent requirements of production from frugal product side and to connect product design to production and supplying strategies

Considering product features as decision criteria for supplier selection strategy will contribute to enhance the product frugal attributes, especially affordable, robust and local attributes. This is given through an optimal balance between cost, quality and delivery time requests, assessed separately for each product module according to its criticality in the target market, impact on the global performance and implication on the final assembly process. The logic is that for critical modules, strong trust on suppliers' performance is required. Less important modules or with high interchangeability allow more flexibility on the selection strategy for cost reduction.

The proposed methodology can provide a great advantage to companies that are moving towards frugal innovation concept by providing local, low-cost and affordable products taking into account local customer's requirements. Moreover, through the consideration of Locality, as criterion, during the proposed supplier's selection and networks design tool, local suppliers can be considered, increasing the market share of local markets.

This paper focuses on the conceptual solution instead of presenting the final implementation for industrial use case which is under development. The developed methodology is well appreciated by industrial partners as well as academic partners.

Acknowledgments. The presented results were conducted within the project "ProRegio" entitled "customer-driven design of product-services and production networks to adapt to regional market requirements". This project has received funding from the European Union's Horizon 2020 program under grant agreement no. 636966. The authors would like thank the industrial partners involved in this research.

\section{References}

1. Zeschky M, Widenmayer B, Gassmann O (2011) Frugal Innovation in Emerging markets: The case of Mettler Toledo. Research Technology Management, vol. 54(4): 38-45

2. Tiwari R, Herstatt C (2012) Frugal Innovation: A Global Networks' Perspective. Swiss Journal of Business Research and Practice, 3: 245-274

3. Berger R (2013) Frugal Products: Study Results. Stuttgart: R. Berger Strategy Consultants http://www.rolandberger.com/media/pdf/Roland_Berger_Frugal_products_20130212.pdf

4. Arndt T, Hochdörffer J, Moser E, Peters S, Lanza G (2015) Customer-driven Planning and Control of Global Production Networks - Balancing Standardisation and Regionalisation. $18^{\text {th }}$ Cambridge Int. Manufacturing Symposium, (UK), 24-25 sept, pp 60-74

5. Hochdörffer J, Arndt T, Bürgin J, Moser E, Scherb M, Lanza, G (2015) Evaluation of global manufacturing networks - a matter of perspective. $19^{\text {th }}$ Cambridge International Manufacturing Symposium, Cambridge (UK), 24-25 sept, pp 327-339

6. Cheraghi S.H, Dadashzadeh M, Subramanian M (2004) Critical Success Factors for Supplier Selection: An Update. J. of Applied Business Research, 20(2): 91-108,

7. http://www.h2020-proregio.eu/ 
8. Du X, Tseng M.M, Jiao J (2003) Product Families for Mass Customization: Understanding the Architecture. The Customer Centric Enterprise Springer-Verlag: Berlin

9. Mourtzis D, Doukas M (2014) The evolution of manufacturing systems: From craftsmanship to the era of customization. Design and Management of Lean Production Systems, V. Modrak, P. Semanco (Eds.), IGI Global, Chapter 1

10. Jiao J.R, Simpson T.W, Siddique Z (2007) Product Family Design and Platform-based Product Development: State-of-the-art Review. Jour. of Intelligent Manufacturing, 18: 5-29

11. Calvi R, Le Dain M, Harbi S, Bonottoo V (2001) How to manage early supplier involvement (ESI) into the new product development process (NPDP): Several lessons from a French study. 10th International Annual IPSERA Conference, Jönköping, Sweden.

12. Bosch-Mauchand M, Belkadi F, Bricogne M, Eynard B (2013) Knowledge based assessment of manufacturing process performance: integration of product lifecycle management and value chain simulation approaches, International Journal of Computer Integrated Manufacturing, 26(5): 453-473

13. Chryssolouris, G (2006) Manufacturing Systems: Theory and Practice. 2nd ed. New York: Springer-Verlag

14. Mourtzis D, Doukas M, Psarommatis F (2012) A Multi-Criteria Evaluation of Centralized and Decentralized Production Networks in a Highly Customer-Driven Environment. CIRP Annals - Manufacturing Technology, 61 (1): 427-430

15. Phadke M.S (1989) Quality Engineering Using Robust Design. Englewood Cliffs, New Jersey, USA: Prentice Hall

16. Mourtzis D, Doukas M, Psarommatis F (2013) Design and Operation of Manufacturing Networks for Mass Customisation. CIRP Annals - Manufacturing Technology, 62: 467-470

17. Mourtzis D, Doukas M, Psarommatis (2015) F A Toolbox for the Design, Planning and Operation of Manufacturing Networks in a Mass Customisation Environment. Journal of Manufacturing Systems, 36: 274-286 